\section{Canadian social trends: a new Statistics Canada social statistics publication}

by D. Craig McKie, Ph.D. ${ }^{1}$

Chief, Social Reporting \& Editor, Canadian

Social Trends

Housing, Family and Social Statistics Division Statistics Canada
'Presented at the International Association for Social Science Information Service and Technology (IASSIST) Conference held in Vancouver, British Columbia, Canada on May 19-22, 1987
In the last ten years at Statistics Canada, the governmental collector and keeper of the nation's storehouse of numerical information about itself, momentous changes have occurred in the ways data are collected, processed, analyzed and published. It is not recognizably the same organization I first joined in 1977. Since that time, the widespread importation of new methods and new technology have in turn been reflected in organizational changes. Accompanying these changes have been pressures to reduce costs and overall staff levels and to recover a larger part of the costs of operation from clients.

While the technical aspects of this change are perhaps better known (and we could refer to random digit dialing-based interviewing techniques, a microcomputer on every other desk, and very sophisticated analytic software and graphics hardware to match it), changes on the publishing side have also been considerable. But while the necessity for modernizing the dissemination of data has been well recognized (by, for instance the widespread acceptance and use of electronic bulletin board type data services and the Bureau's own service CANSIM, and by sales of data on floppy disks, user tapes, and other similar services), publishing has not received quite the same amount of attention. The Bureau, for instance, still publishes many strange and exotic publications such as: the Cereals and Oilseeds Review, Gas Utilities, The Dairy Review, and last but not least, Sawmills East of the Rockies.

However, the number of users of whatever origin who are ready to plow through table upon table to find a single figure - or to construct their own annual time series from 25 years of monthly pamphlets is limited. Further, many users have neither the time, the training, nor the inclination to do such work.

Those who decline to engage in such activities are legion. Some telephone me; undoubtedly some may telephone some of you. Indeed, at 
the recent meetings of the Population

Association of America in Chicago, one eminent demographer, who shall remain unnamed, stated to one of my colleagues that it was easier to obtain Zambian data than to get it from Statistics Canada.

Such reactions are not uncommon. Foreign nationals, or the inexperienced, simply do not know where to begin. Other domestic users, although they know how to begin, lack the iron will necessary to persist in their quest. They tend to fall into several broad categories of persons. Three prominent types are:

1. those who are interested in a subject but lack the knowledge of how to go about finding suitable data and who are intimidated by the traditional publication of official statistics [massive cryptic tables with lots of footnotes, runic symbols, and qualifications which seem meant to undermine any simple interpretation of the contents];

2. those who know what they want and where to find it but cannot afford the time to assemble the data nor interpret it [there are few who do not shudder at the task of sorting through 52 pages of tables, the numbering of which may change from year to year, over enough years to assemble a graph which can indicate the direction of change, perhaps standardized to some rate per population];

3. those who don't want data at all but rather a prose summary of a data set to use as evidence.

I think it was our belief when we started to think about the form of what turned out to be CSI, in 1984, that most Canadians, to the extent that they seek to use Statistics Canada material, fall into one of these three categories or subsets of them. To reach such people with useful information, a new format would be necessary. Our subsequent activities in search of such a format have been based on the premise that there is a significant demand from a wide range of governmental and non-governmental agencies for comprehensive and systematic information which identifies, describes, and analyzes social trends and conditions in Canada. This demand is expressed in a number of ways including requests to Statistics Canada for assistance, information, and ideas. These requests come from government agencies, members of parliament, community groups, and the press. Canadian Social Trends is one response to these requests.

There is much potential for information which illuminates the social conditions which are the objects of policies, programmes, and public concern. After some trial and error, which involved the preparation of a similar annual format (it was discarded because of the inevitable loss of timeliness in an annual publishing cycle), the final decision was to go with a quarterly format which at least superficially looks like a news magazine - a format familiar to almost everyone in western countries and one users expectations of which are in a sense built-in. One expects succinct, highly graphical treatment of issues pertinent to the reader (they are not arcane) interspersed with advertising (information).

The start of publication of Canadian Social Trends is one notable aspect of the latter type of change.

\section{The New Publication}

In terms of the number of its publications (in excess of 600) Statistics Canada could well be the largest publisher, public or private, in Canada. However, its publications have by tradition been dry and heavily given to technical 
detail. In contrast, Canadian Social Trends is an entirely new type of publishing endeavour for Statistics Canada.

The purpose of CST is to report on changing social conditions in Canada in order to provide government and corporate policy-makers and planners, marketers, and others with a basis for decision-making. It provides recent and historical evidence for the direction and magnitude of change of important social trends. Its intent is to describe and make evident a trend's inter-relation with policy concerns, and promote an understanding of social conditions (and economic developments where a direct social outcome is established).

The publication has five distinct objectives:

1. to provide decision-makers in government, industry, and the social service sector with an awareness of social and socio-economic trends and information relevant to their environment in an appealing format. Improving accessibility to Statistics Canada information and information products is the prime objective;

2. to provide users with a single, authoritative source for social trend description and analysis in an easily accessible and readable form. The intention is to integrate sets of data and make the connections between isolated findings;

3. to provice committed information users with information about Statistics Canada's data holdings, information products, and services;

4. to provide Statistics Canada with a flagship with which to raise public awareness of its corporate character, value, and contributions to the public interest. The publication supports the data collection process by showing a public return of information to respondents - this return helps justify impositions on respondents' time:
5. to provide a vehicle with which to publicize the existence of Statistics Canada information and data products and statistical services to get the greatest possible use from a considerable investment of public funds in data collection while at the same time earning revenues to help defray the costs.

Audiences foreseen or already realized for this publication are: policy-makers and planners, both governmental and corporate, social service agencies, educators engaged in teaching social or Canadian studies at the secondary or post-secondary level, libraries, the media, international information repositories, and market research concerns.

Subject matter is selected according to a loose formula. In each issue there should ideally be found one article on each of the following general topics: demography, labour force, and. income. In addition, a rough rotation of issue selection exists with respect to institutional areas (e.g. culture, health. education, and justice); and with respect to target groups (i.e. women, the elderly, youth, native peoples, and the disabled).

\section{New Presentation Styles}

It is difficult in words to describe style. Therefore I will show you some before and after shots of the same data in the old and the new format. (see examples collected together at the end of this article. Ed. note).

Now entering its second year of publication, CST is intended to be the authoritative voice for Canadian social statistics as they are collected and disseminated by Statistics Canada. The quarterly publication attempts to place social statistical reporting on a much more accessible basis than was previously the case. It 
carries analytical articles of varying lengths on important topics of social statistical reporting (such as the decline in fertility and the increase in lone parent families). Each edition of the report is approximately 44 magazine format pages long and features text written for the educated layman. With 25 - 30 graphics per issue (photographs and illustrative drawings), it is primarily intended to be used as the best source of Canadian social trends material for government policy makers, planners, and private sector marketing specialists in addition to students. There are no private sector publications which compete with CST. As a result, it has quickly become the obvious source for Canadian social statistical data and carries new analyses and data reporting in addition to publishing summary articles on previously released data. In addition, each edition carries a social indicators page and notices of the release of new Statistics Canada publications which might be of interest to readers.

What is really novel about this publication is that it is a clear departure from the usual 'muiti-table and short descriptive text' format traditionally associated with governmental statistical publications. Early acceptance of the format has been much greater than initially expected: Canadian Social Trends already has the largest paid subscription of any Statistics Canada periodical publication and indications are that interest outside the country is high, perhaps reflecting the fact that for a foreign reader unfamiliar with Canadian social statistics, this publication is in most senses self-explanatory, carrying with the articles the definitions and data qualifications necessary for reuse without further reference to sources. A three hour audio-visual presentation is also available to clients for a fee when resources are available.

Underlying the publication is a time series database containing some thousands of series. At some point in the future, clients will be able to purchase collections of these series, on diskette in Lotus format, thus greatly shortening their data collection and processing times and reducing the cost of data acquisition accordingly.

The publication is put together by a full time staff of six people, including myself, with the assistance of a professional design firm and students from Canadian university co-operative programmes. At any given time, we have from two to four university students on work term assignments. They receive course credit for working for the project In addition, we employ some contract writers and editors, although the bulk of the editorial content is generated from within Statistics Canada.

The publication is issued in both official languages. Page design is by a contract design firm.

Examples

I will use the remaining time available to me to show you some concrete examples of what we mean by social trends. (see examples collected together at the end of this article. Ed. note). They may be thought of as significant changes of direction in the measures of significant social institutional variables. 


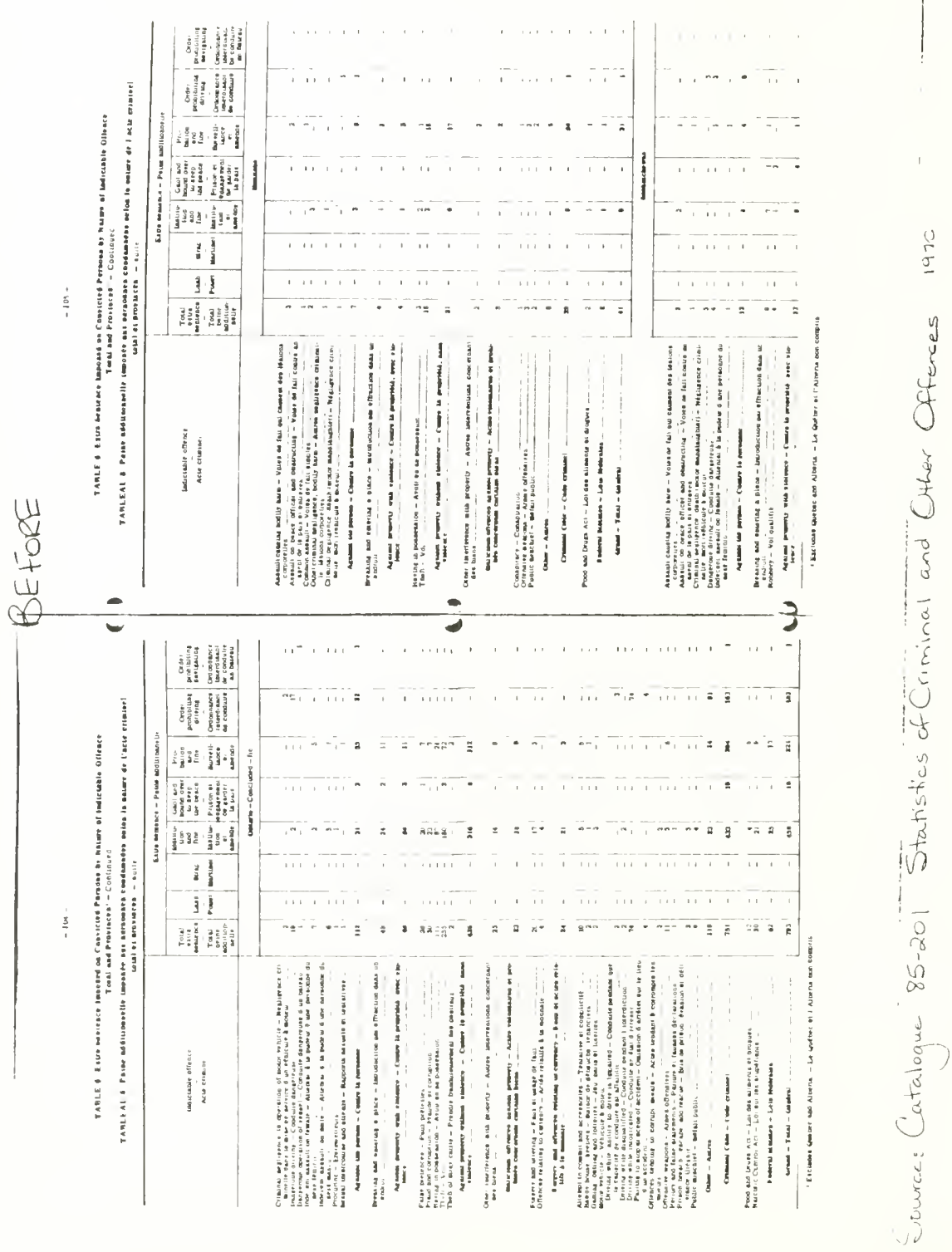



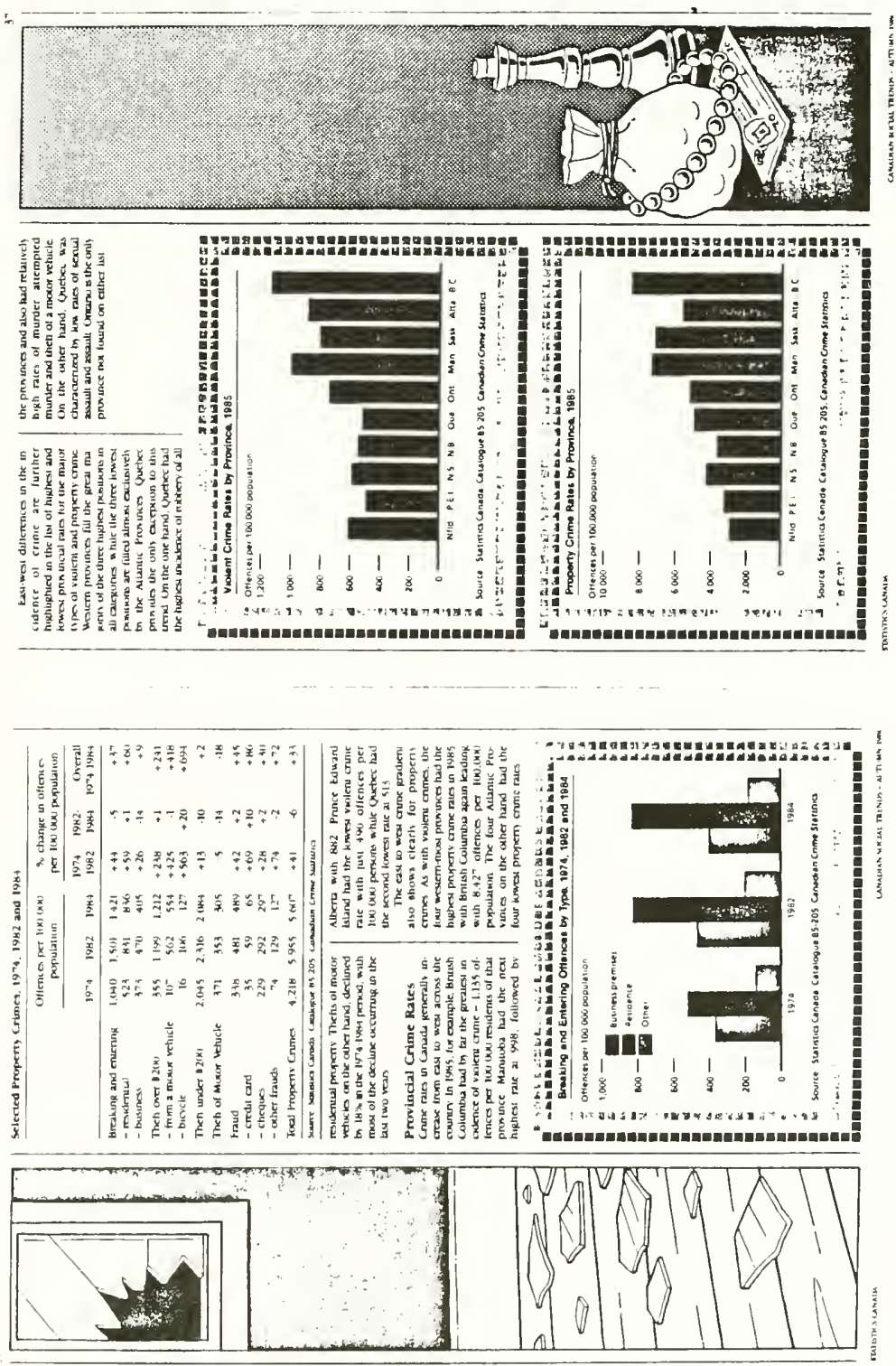


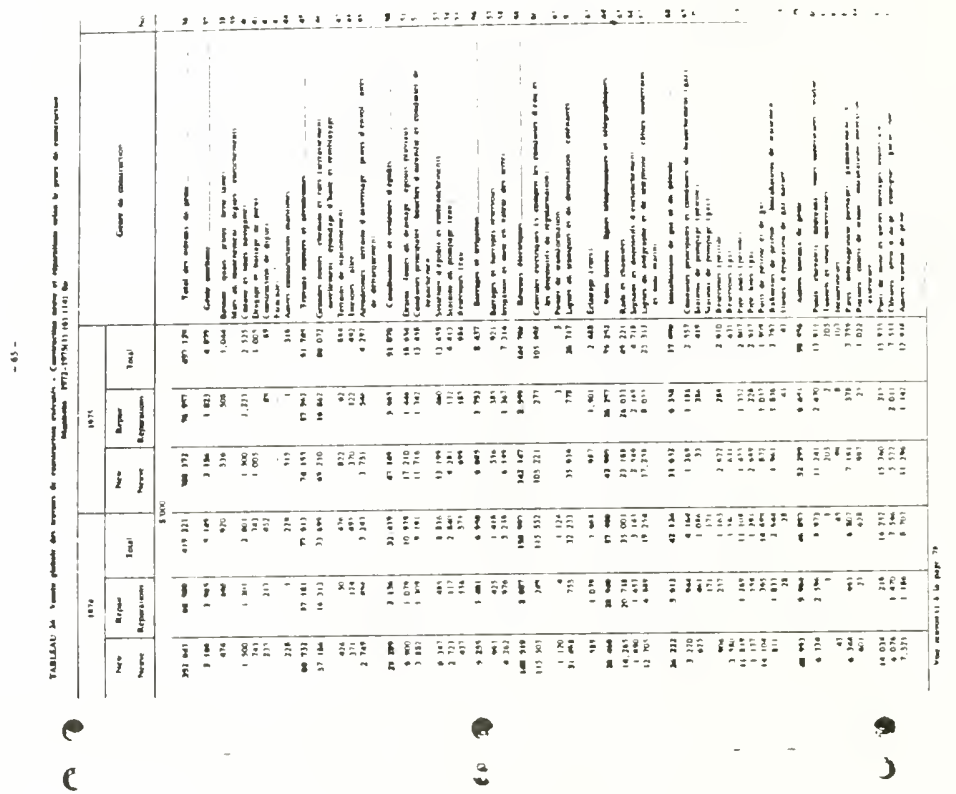

$\frac{1}{4}$

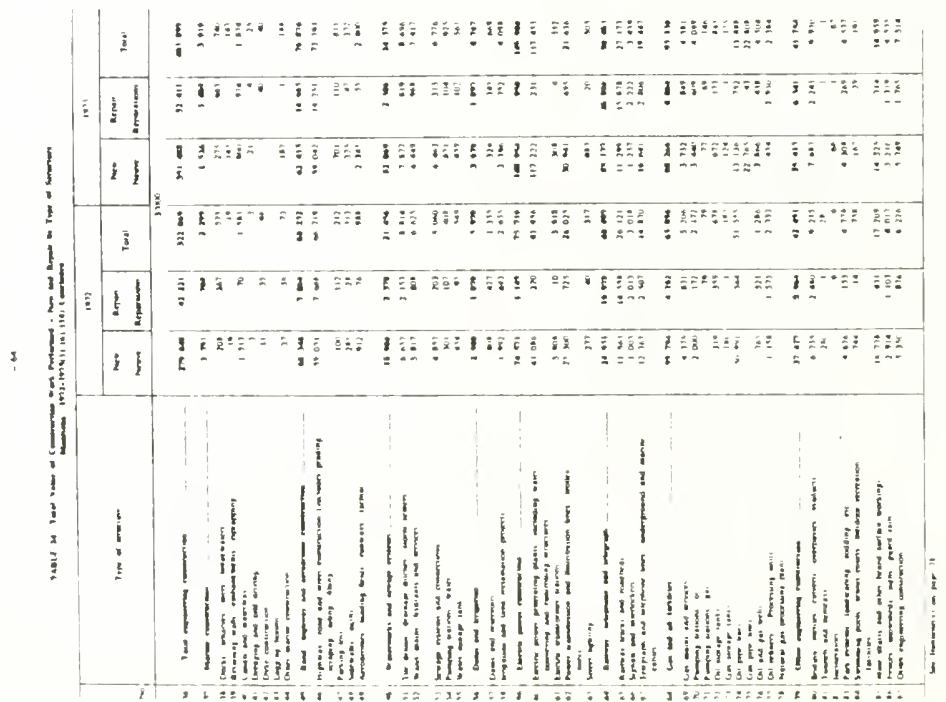



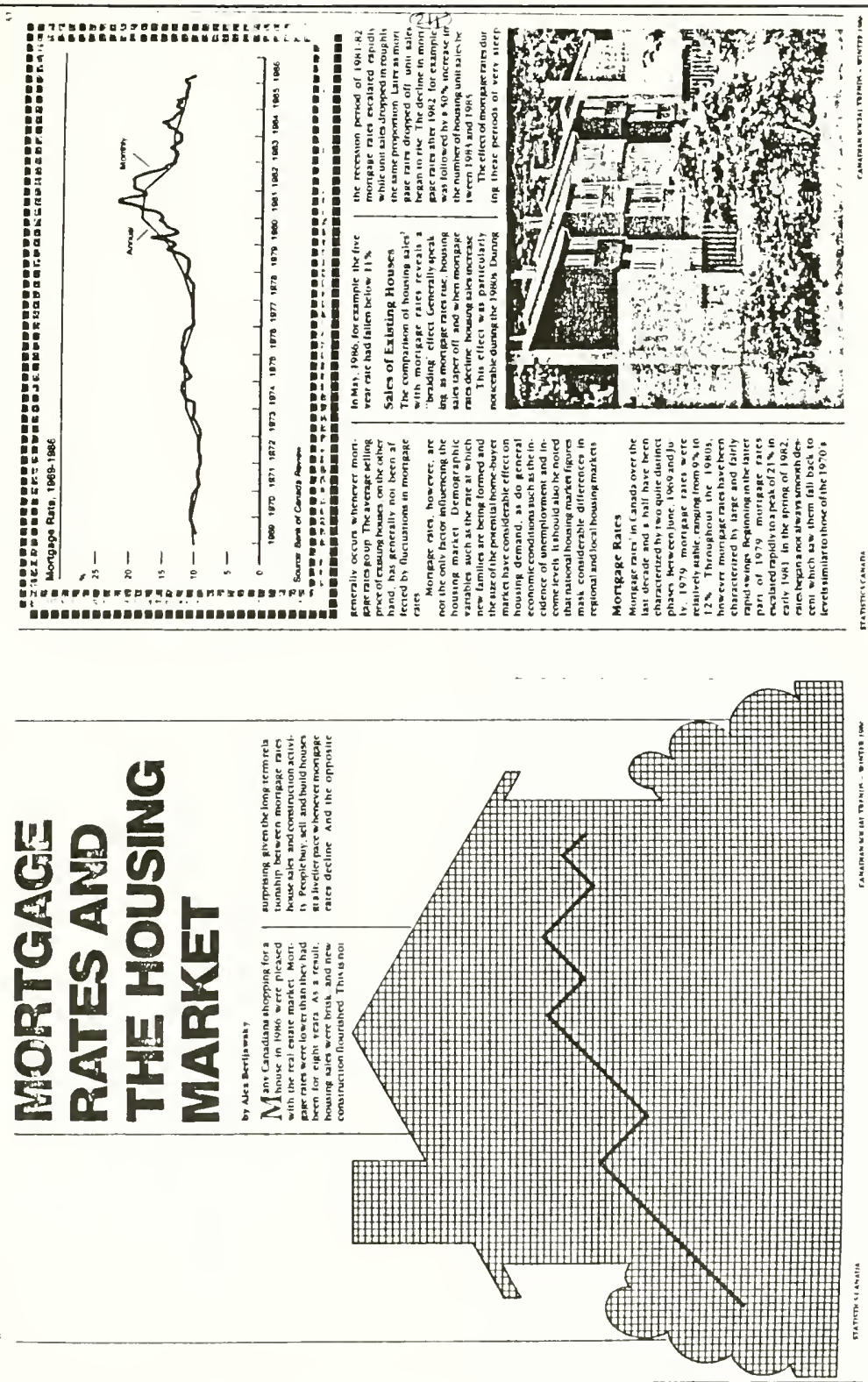


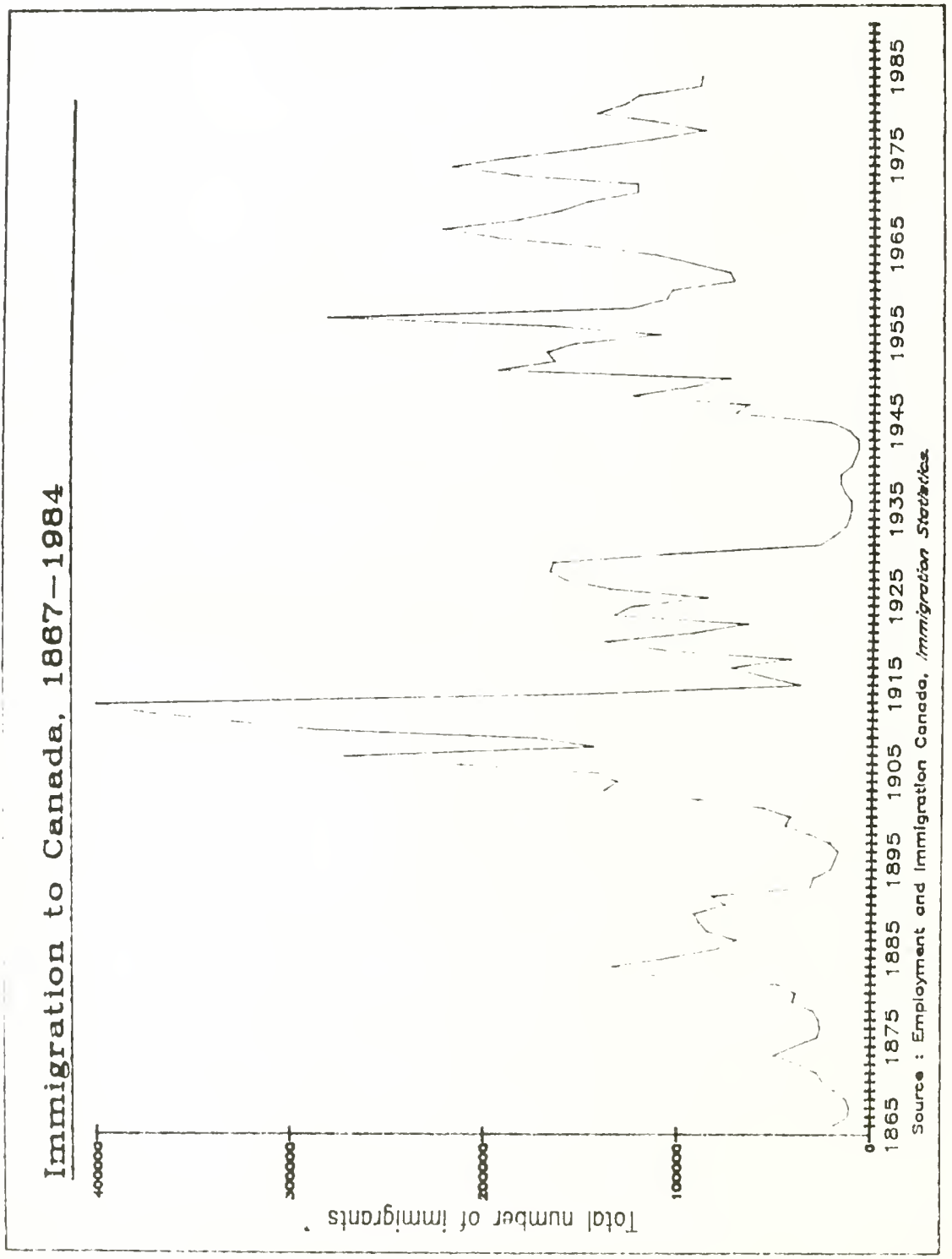




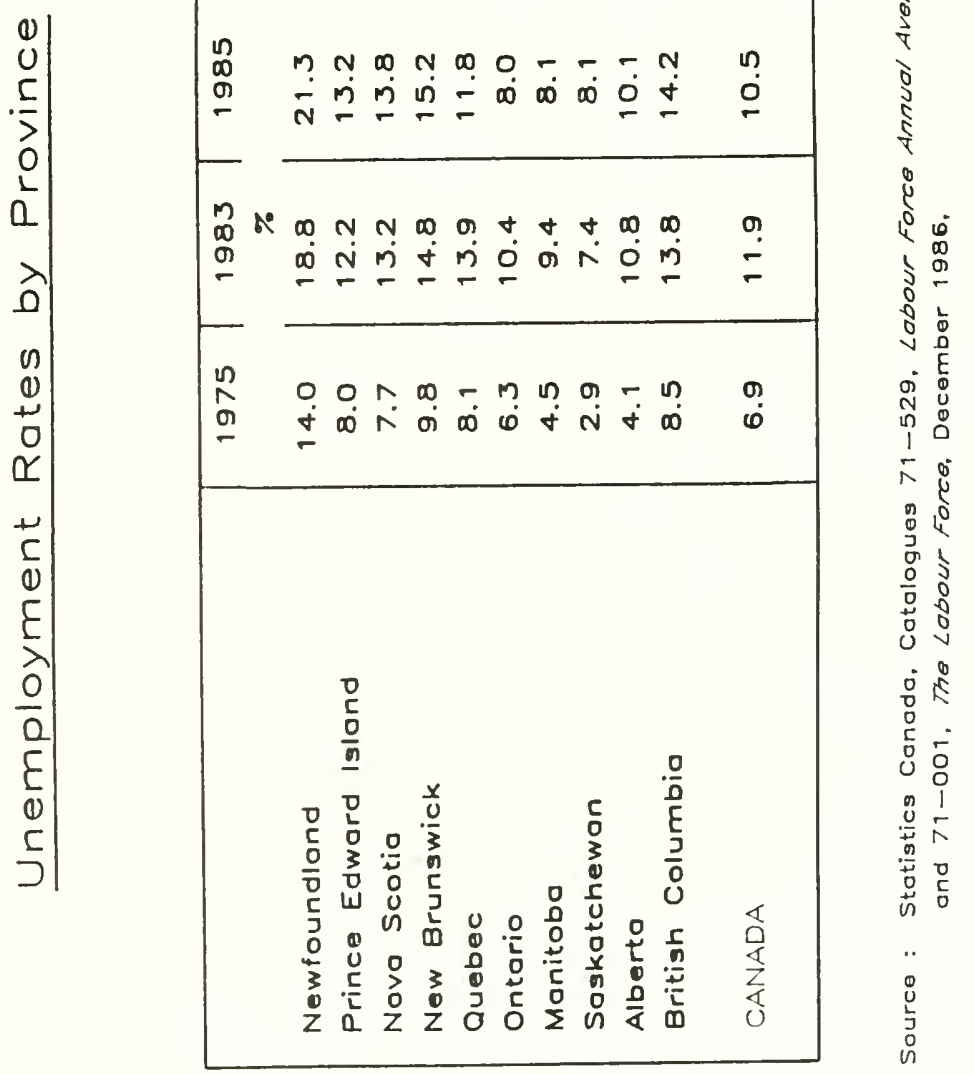




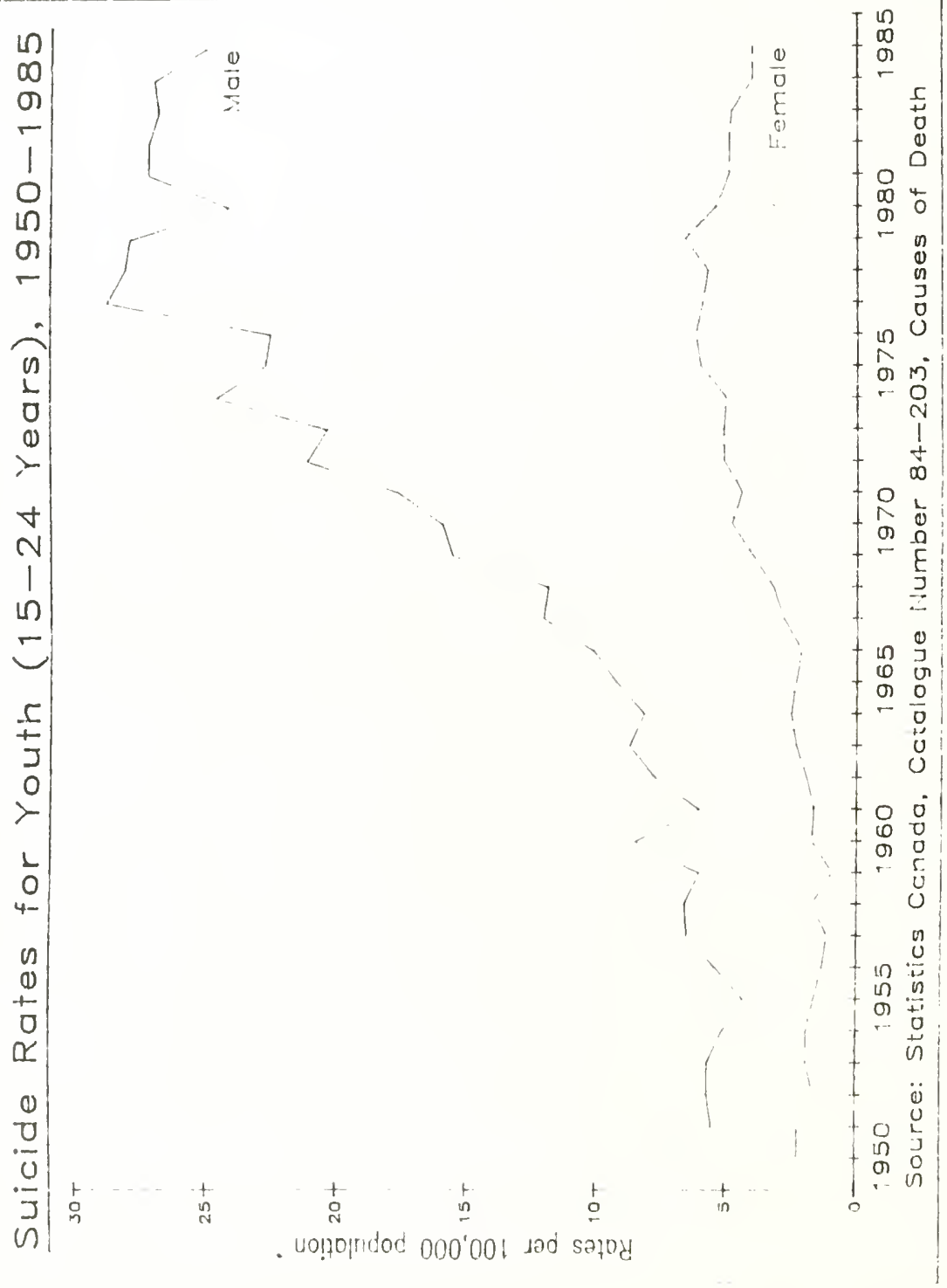




\section{Population Distribution by Regions}

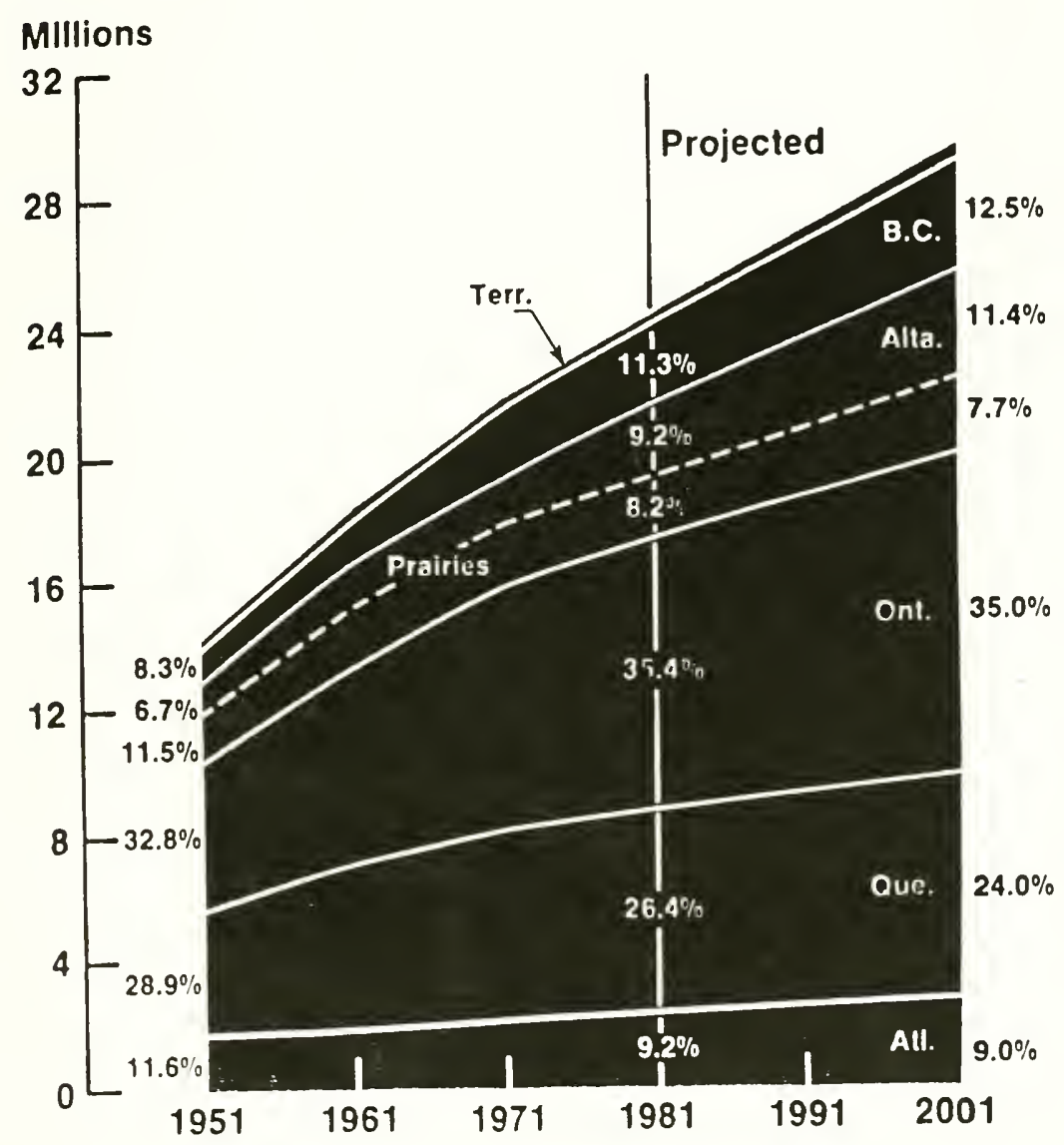




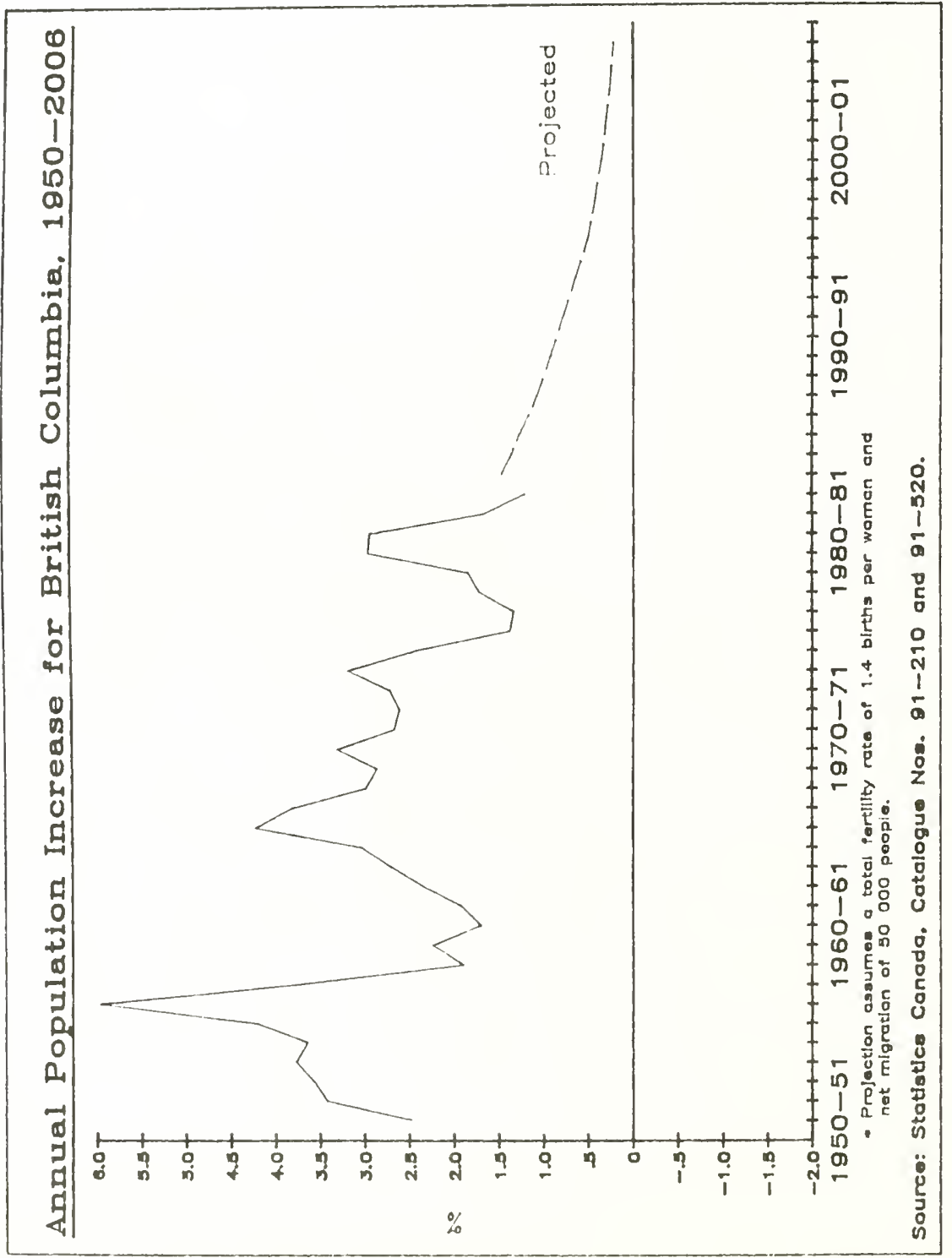


<smiles>C1=CC2CCCCC2C1</smiles> 

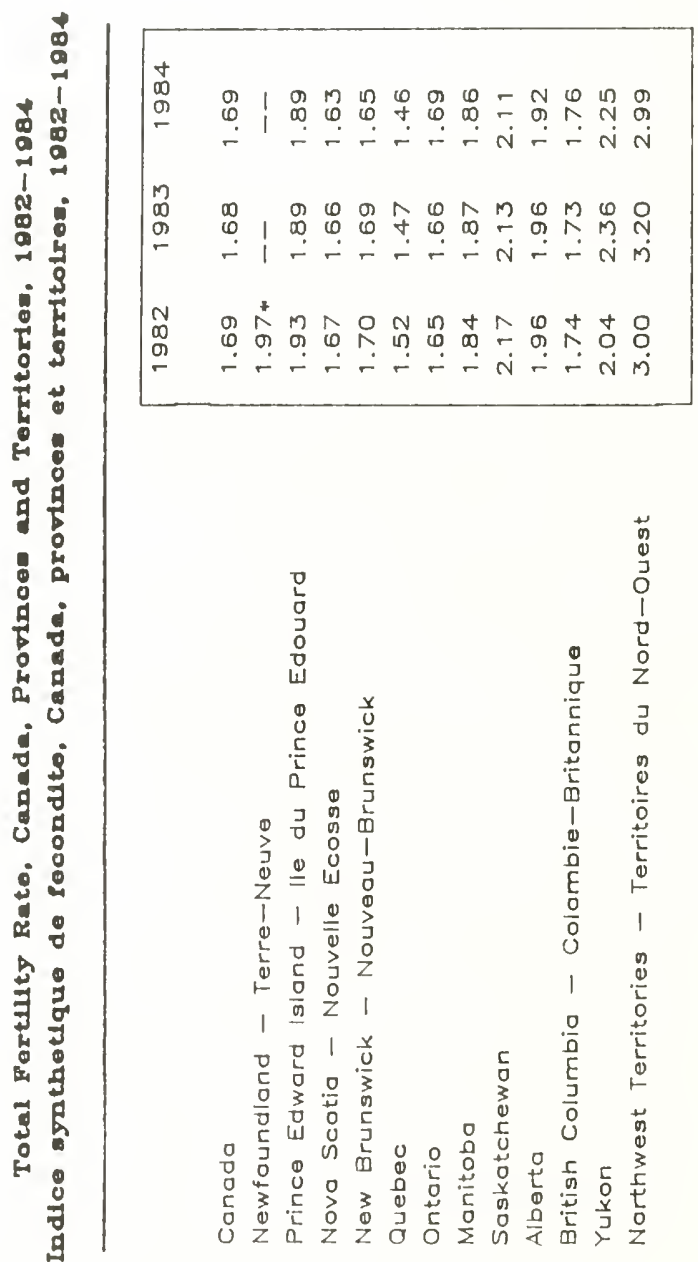


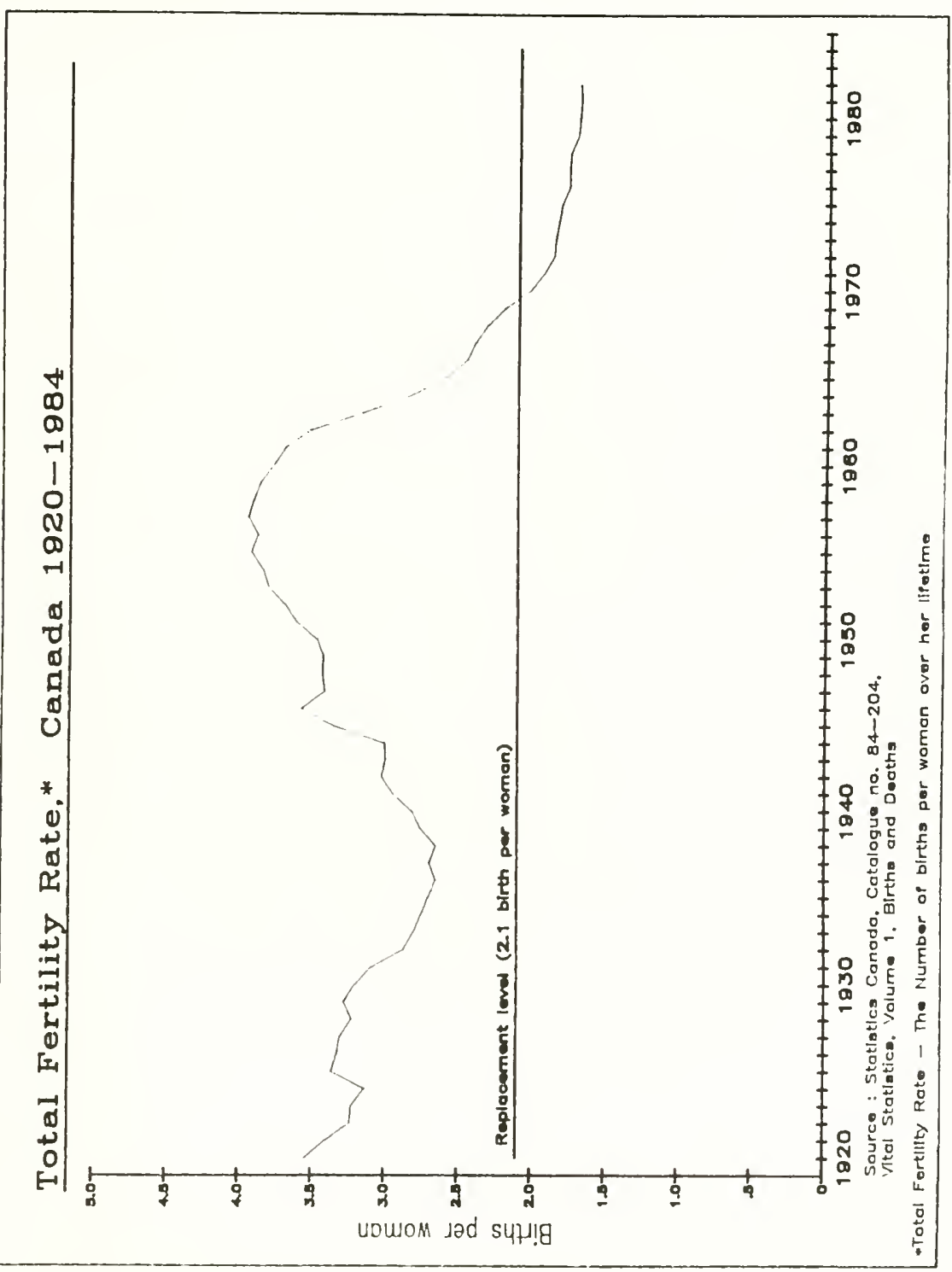




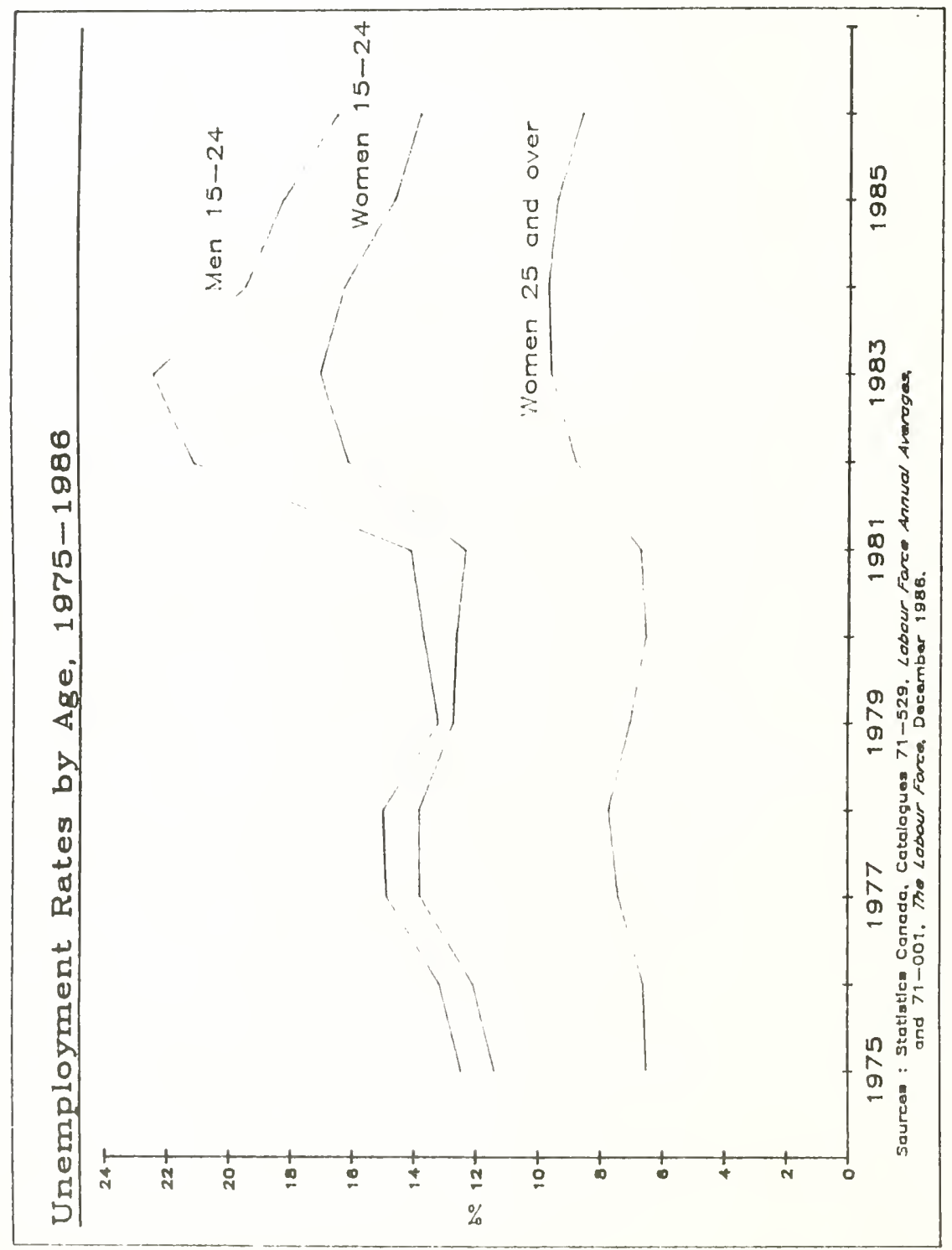


iassist quarterly

$-35$

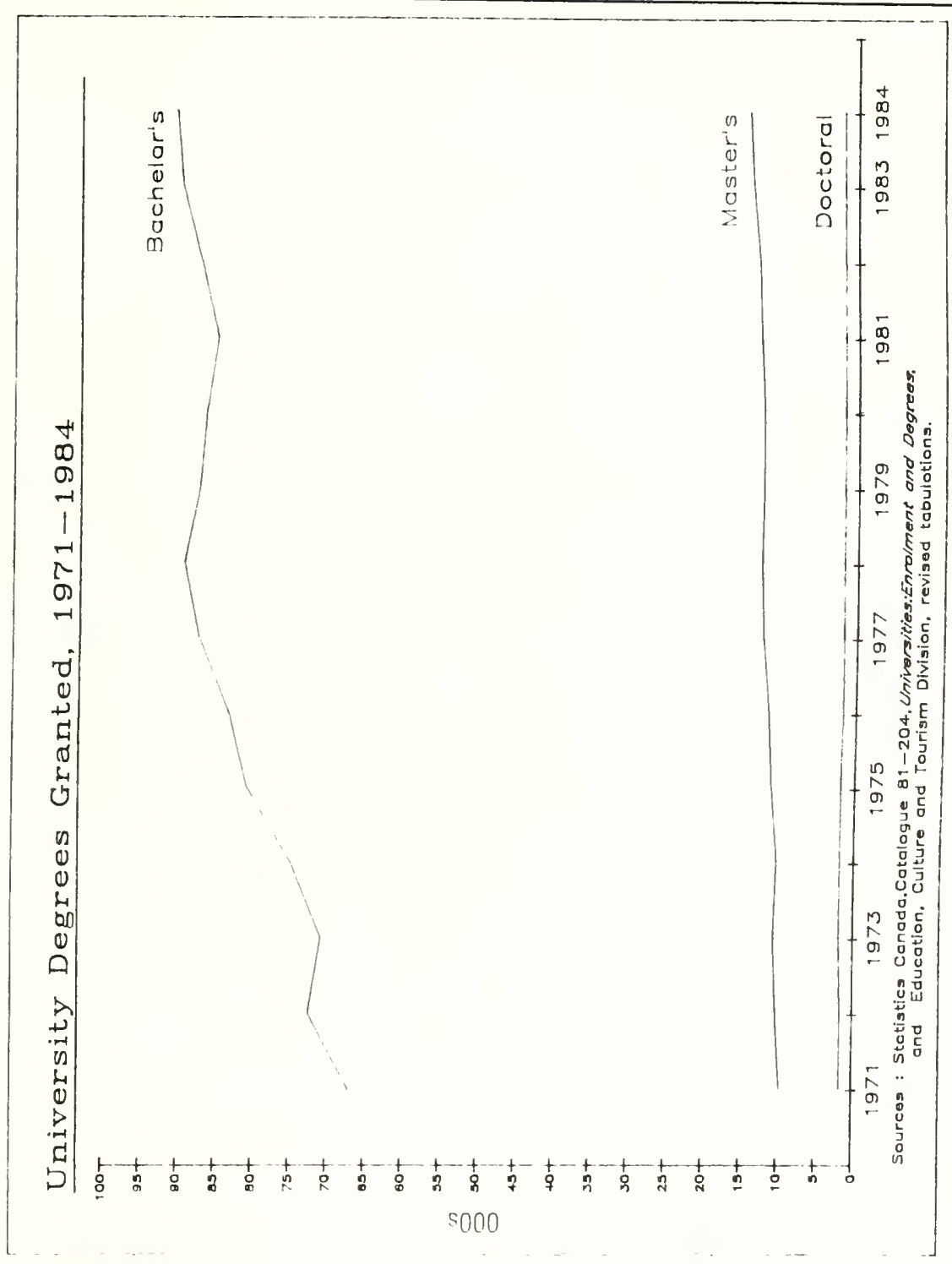

Fall/Winter 1987 


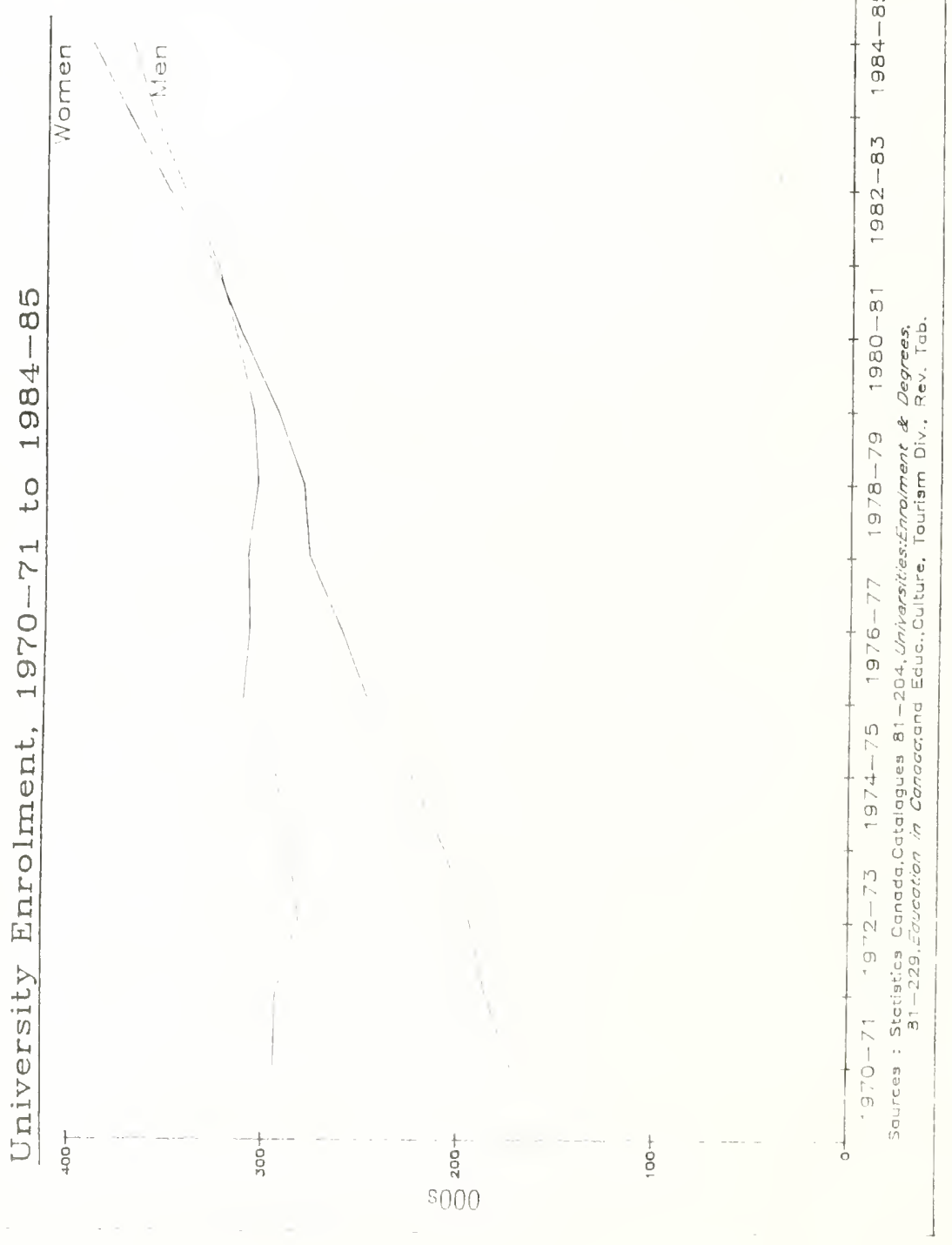




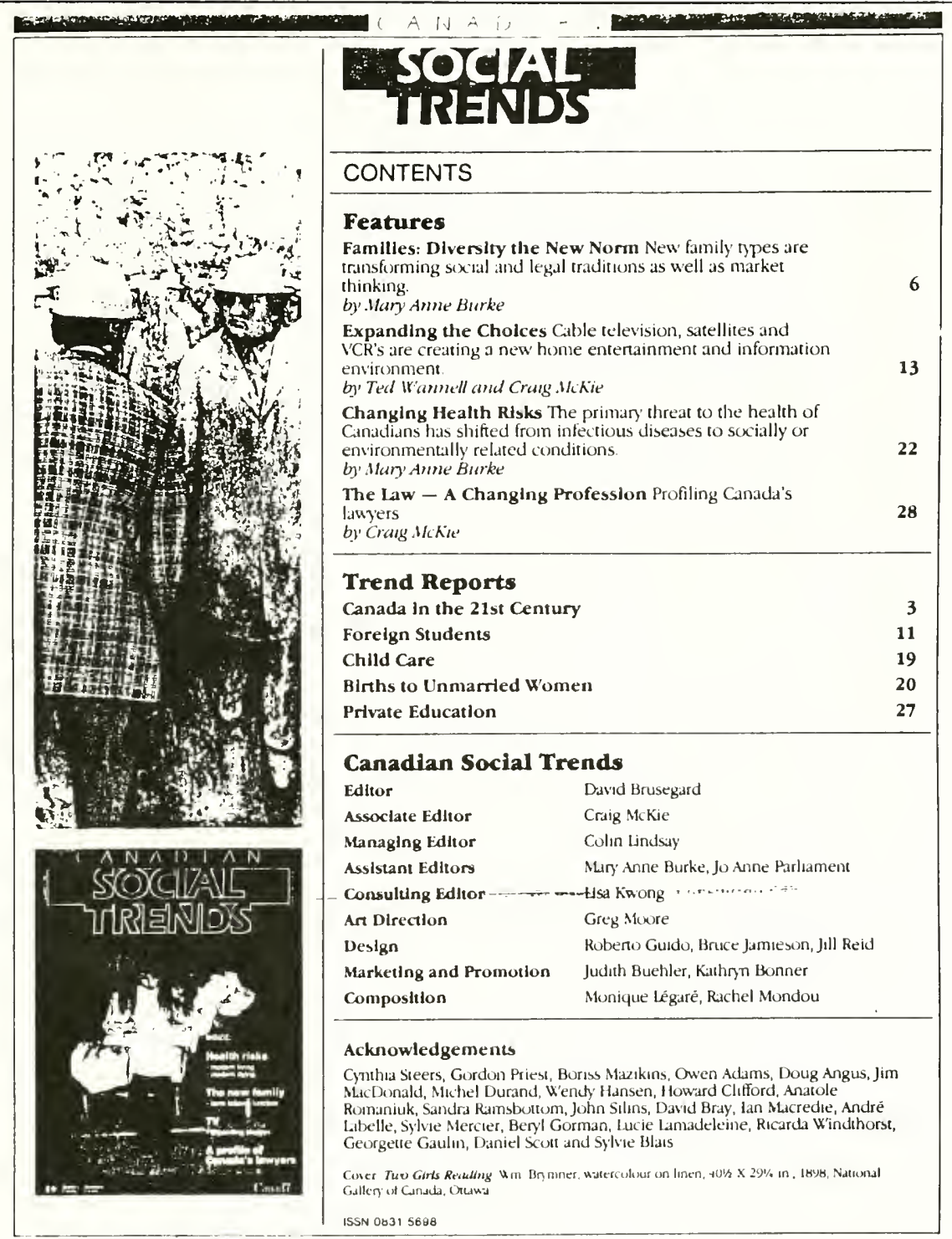




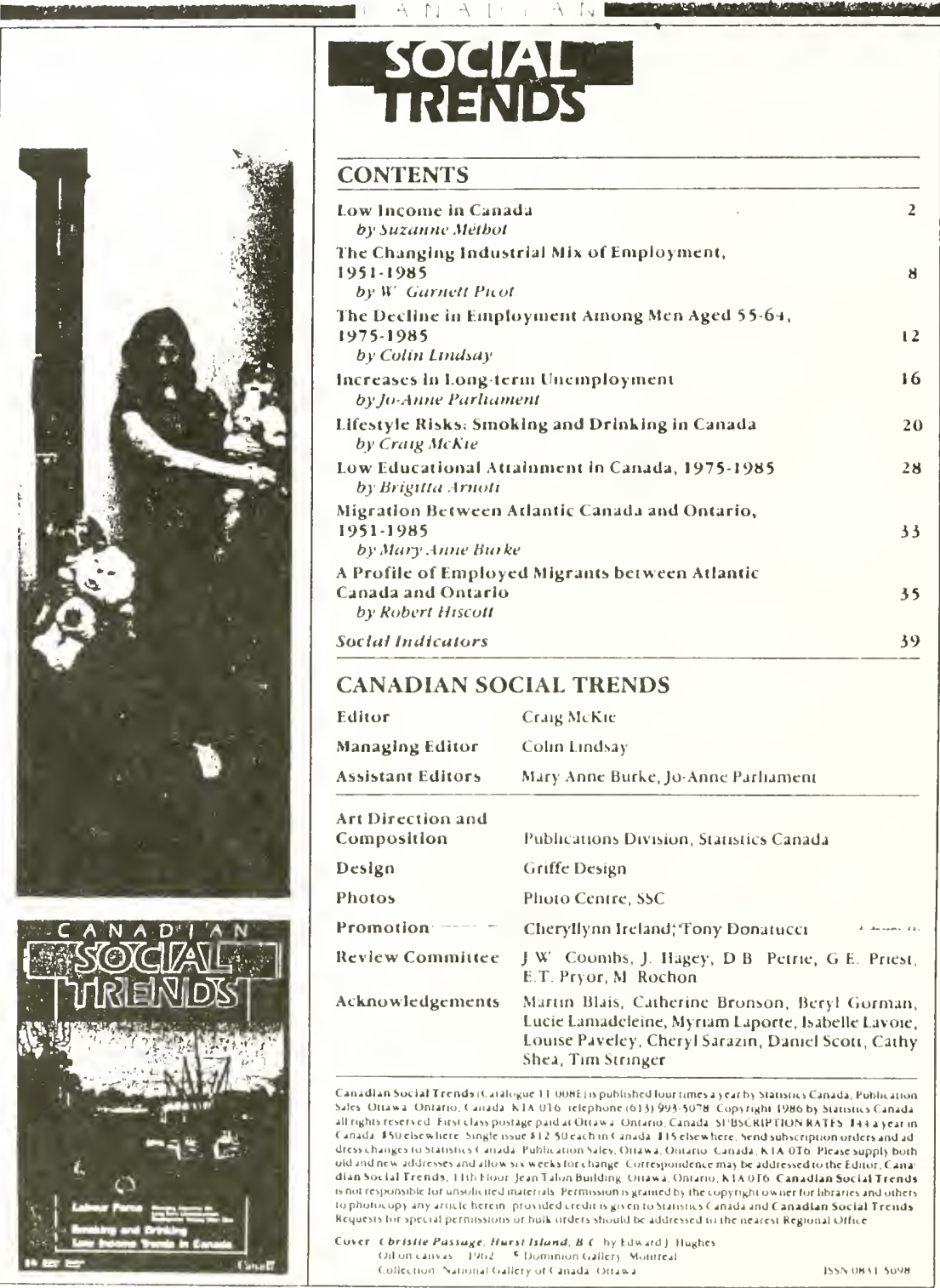




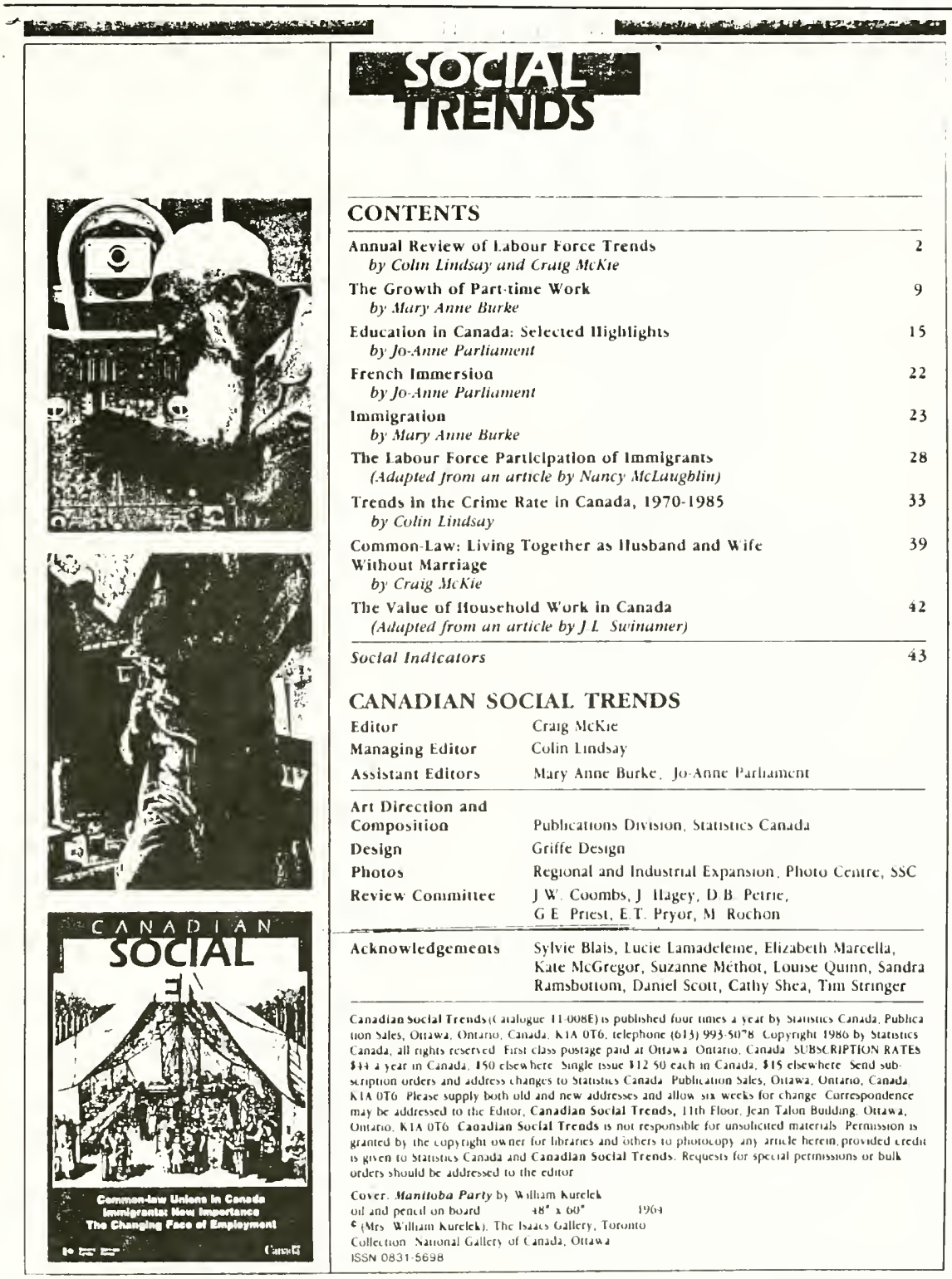

